\title{
Tijdreizen: een gespreksgroep tussen jong en oud als onderwijsinstrument
}

Als gevolg van de vergrijzing van de samenleving krijgen studenten gezondheidszorg in hun stage en latere beroep steeds meer te maken met ouderen. Omdat er buiten de familie maar weinig contact bestaat tussen jongeren en ouderen zijn studenten weinig vertrouwd met de belevingswereld van ouderen. Het gevaar bestaat dat zij ouderen op een stereotiepe manier tegemoet treden. De gespreksgroep Tijdreizen brengt studenten met ouderen in contact. Door het vertellen van verhalen over het eigen leven nemen jong en oud elkaar mee op reis door de tijd. Deelnemers ervaren dat er minder generatieverschillen zijn dan ze dachten en ze leren dat er grote diversiteit is binnen elke leeftijdsgroep. De gespreksgroep Tijdreizen kan aangeboden worden als onderdeel van een curriculum zorg en welzijn of als onderdeel van een stage.

Gerben Westerhof, Karen van Kordelaar, Astrid Vlak en Yolande Kuin *

\section{Achtergrond}

De laatste tijd staat de vergrijzing van de samenleving volop in de belangstelling. De komende jaren zal de groep mensen die tijdens de geboortegolf na de tweede wereldoorlog het levenslicht zag, oud worden. Cijfers van het Centraal Bureau voor de Statistiek laten zien dat de komende dertig jaar het aantal 65-plussers bijna zal verdubbelen van 2,4 naar 4,3 miljoen. Een kwart van de 17 miljoen Nederlanders zal dan ouder zijn dan 65 jaar.

In verschillende opleidingen komt op grond van deze vergrijzing meer aandacht voor ouderen. Zo zijn de afgelopen jaren verschillende lectoren op het gebied van de gerontologie aangesteld en is onlangs vanuit de HBO-raad en Arcares een competentieprofiel Verpleegkundige Gerontologie en Geriatrie opgesteld (Pool \& Schumacher, 2005).

Eén van de gevolgen van de vergrijzing is ook dat de huidige studenten gezondheidszorg steeds meer met ouderen te maken zullen krijgen in hun beroep. Omdat er ook steeds meer gewerkt wordt vanuit de persoonlijke wensen en behoeften van cliënten en patiënten, is het van belang dat studenten goed inzicht hebben in de belevingswereld van ouderen. Door

Ik heb het idee dat ouderen in het verleden blijven steken en de boel idealiseren. Als ze nou eens een beetje mee gingen met de tijd, dan hadden we ook meer raakvlakken om over te praten. (Kim, 19 jaar) de American Psychological Association (2004) is dit voor psychologen die met ouderen gaan werken ook expliciet zo gesteld.

Het is echter de vraag of studenten dit inzicht al hebben. Buiten de familie is er weinig contact tussen jongeren en ouderen. Onderzoek liet zien dat bijna twee op de drie Nederlandse ouderen weinig, zelden of nooit contact heeft met jongeren onder de 25 jaar (Walker \&
Maltby, 1997). In een ander onderzoek werd gevonden dat het sociale netwerk van 65plussers vijftig keer minder mensen onder de 25 jaar omvat dan op grond van de leeftijdsverdeling van de Nederlandse bevolking verwacht mag worden (Hagestad \& Uhlenberg, 2005). Ouderen zien mede daardoor de maatschappij als van de jongeren en hebben het gevoel langs de zijlijn te staan (Van Kordelaar \& Westerhof, 2007).

Dit gebrek aan contact komt onder andere doordat onze maatschappij sterk naar leeftijdsgroepen is opgedeeld (Riley \& Riley, 1994). Zo bestaan er allerlei wetten, regels en

Ouderen zijn vaak eenzaam en als je dan een keer een praatje met hen maakt, dan blijven ze maar door kletsen.

Ik denk dat ze weinig om handen hebben. (Vera, 17 jaar)

voorschriften waarin leeftijd een belangrijke rol speelt. Het gaat daarbij voor jongeren met name om zaken als leerplicht, rijbewijs mogen halen, en kiesrecht verwerven. Voor ouderen gaan veel regels en wetten over pensionering. In zekere zin zou men zelfs kunnen spreken van een nieuwe verzuiling. Het medialandschap wordt verkaveld naar leeftijdsgroep (denk aan BNN en Max, Flair en Plus, Seniorenweb). Het vrijetijdsaanbod richt zich 
specifiek op jongeren of ouderen (het jeugdorkest en de senioren-fitness; de jongerenreis en de ouderenreis; de jongerendagen en de 50+-beurs). Er zijn zelfs bonden en partijen die zich als belangengroepering voor een bepaald leeftijdssegment opwerpen (bv. FNVjong of ouderenbonden). Op een informeel niveau hebben mensen ook allerlei opvattingen over wat wel en niet hoort bij een bepaalde leeftijd: welke kleding men aan kan, welke haardracht passend is en welk taalgebruik men bezigt.

Het gebrek aan contact tussen jongeren en ouderen heeft tot gevolg dat zij zich vaak op stereotypen baseren (Westerhof \& Tulle, 2007). Ouderen worden daarbij vaak positief beoordeeld als het gaat om hun persoonlijkheid of hun sociale vaardigheden. Ze worden echter in vergelijking met jongeren negatief beoordeeld als het gaat om hun fysieke aantrekkelijkheid, hun gezondheid en hun competenties (Versteegh \& Westerhof, 2007). Jongere stagiaires en professionals in de verpleging en verzorging lopen de kans dat de negatieve beelden over ouderen bevestigd en uitvergroot worden, omdat zij veelal met kwetsbare en zorgafhankelijke ouderen in contact komen. Onderzoek heeft laten zien dat met name deze professionals sterke negatieve stereotypen over ouderen hebben (Beullens et al., 1997). Deze stereotypen kunnen leiden tot betuttelend en paternalistisch gedrag, waarin de wensen en behoeften van ouderen niet meer serieus genomen worden (Westerhof \& Tulle, 2007).

Zodra jongeren persoonlijke informatie over ouderen krijgen, wordt hun houding ten opzichte van deze groep minder stereotiep en minder negatief (Kite \& Johnson, 1988). Het is dan ook van belang om studenten al in een vroegtijdig stadium persoonlijk met ouderen in contact te brengen. Daarbij is het van belang dat zij ook met vitale ouderen kennis maken om te voorkomen dat negatieve stereotypen bevestigd worden (Beullens et al., 1997). De gespreksgroep Tijdreizen biedt hiertoe de mogelijkheid.

\section{Doelen en methodiek}

De gespreksgroep Tijdreizen heeft als doel om jongeren en ouderen kennis te laten maken met elkaars belevingswereld (Van Kordelaar, Vlak, Kuin \& Westerhof, 2007). Voor jongere studenten draagt de gespreksgroep bij aan een minder stereotiepe benadering van ouderen in hun praktisch werk met deze doelgroep. Daarnaast is het doel voor de stu- denten om te oefenen in het opzetten en begeleiden van gespreksgroepen. Voor ouderen draagt de gespreksgroep bij aan een betere kennis over de jongere generatie en aan het vinden van een balans tussen het goede van vroeger en de mogelijkheden van de hedendaagse samenleving.

Om deze doelen te bereiken is er een werkboek ontwikkeld met veertien gespreksthema's. De thema's zijn gebaseerd op theorieën over levensloopontwikkeling enerzijds en op de mogelijkheid voor uitwisseling tussen generaties anderzijds. De gekozen thema's bieden de mogelijkheid om de eigenheid van elke persoon naar voren te laten komen, ze zijn interessant voor mensen van verschillende leeftijden en ze bieden aanknopingspunten om verschillen en overeenkomsten tussen generaties vast te stellen. De veertien thema's vallen uiteen in vier groepen:

\begin{tabular}{|c|c|c|c|}
\hline \multicolumn{4}{|c|}{ 1. Leven in de tijd } \\
\hline Stereotypen & Levensloop & \multicolumn{2}{|l|}{ Huidige levensfase } \\
\hline \multicolumn{4}{|c|}{ 2. Leven in een veranderende samenleving } \\
\hline $\begin{array}{l}\text { Nederlandse } \\
\text { samenleving }\end{array}$ & $\begin{array}{l}\text { Waarden } \\
\text { en normen }\end{array}$ & Tradities & Taboes \\
\hline \multicolumn{4}{|c|}{ 3. Leven in relaties met anderen } \\
\hline Opvoeding & Familierelaties & Vriendschappen & \\
\hline \multicolumn{4}{|c|}{ 4. Leven in eigen hand } \\
\hline Keuzevrijheid & Levenskunst & $\begin{array}{l}\text { Levensovertuiging } \\
\text { en zingeving }\end{array}$ & Identiteit \\
\hline
\end{tabular}

Elk thema bevat een inleidende tekst, thuisopdrachten en vragen, opdrachten en stellingen voor het groepsgesprek. De inleidende teksten zijn bedoeld om richting te geven aan het thema. Door middel van thuisopdrachten, die bestaan uit verdiepende en inzichtgevende vragen, kunnen de deelnemers voorafgaand aan het groepsgesprek zelf gedachten vormen. Zij doen dit zonder dat de ervaring, beleving en ideeën van andere deelnemers dit vertroebelen. In het groepsgesprek wisselen de jongeren en de ouderen onder leiding van een gespreksleider hun ervaringen rondom het thema uit. Ze doen dit aan de hand van verschillende vergelijkingen: vergelijkingen tussen levensfasen (wat betekent het om jong of oud te zijn), vergelijkingen tussen jong zijn vroeger en jong zijn nu, vergelijkingen tussen de maatschappij van vroeger en die van nu en tot slot vergelijkingen tussen individuele personen.

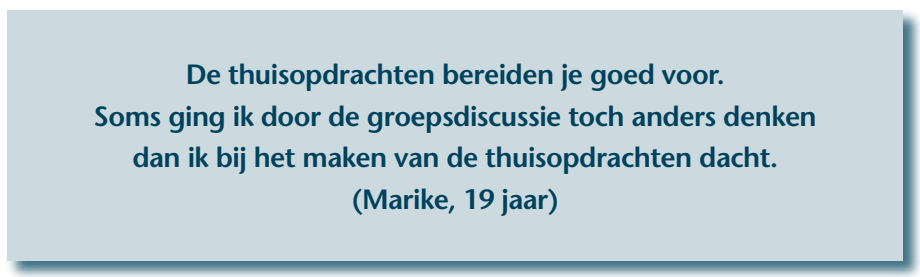

De gespreksgroep is zodanig opgezet dat de thema's voor elke groep flexibel gekozen kunnen worden. Het is aan de onderwijsinstelling om het gewenste aantal thema's te selecteren. Wel is aan te raden om altijd een kennismakingsbijeenkomst en tenminste vier themabijeenkomsten van ongeveer anderhalf uur te organiseren. Dit komt ten goede aan het groepsproces en zal de impact van de themagesprekken op de individuele deelnemers vergroten.

Een gespreksgroep bestaat uit vier of vijf studenten en vier of vijf ouderen. Naast de deelnemers zal er nog een (extra) student zijn die 


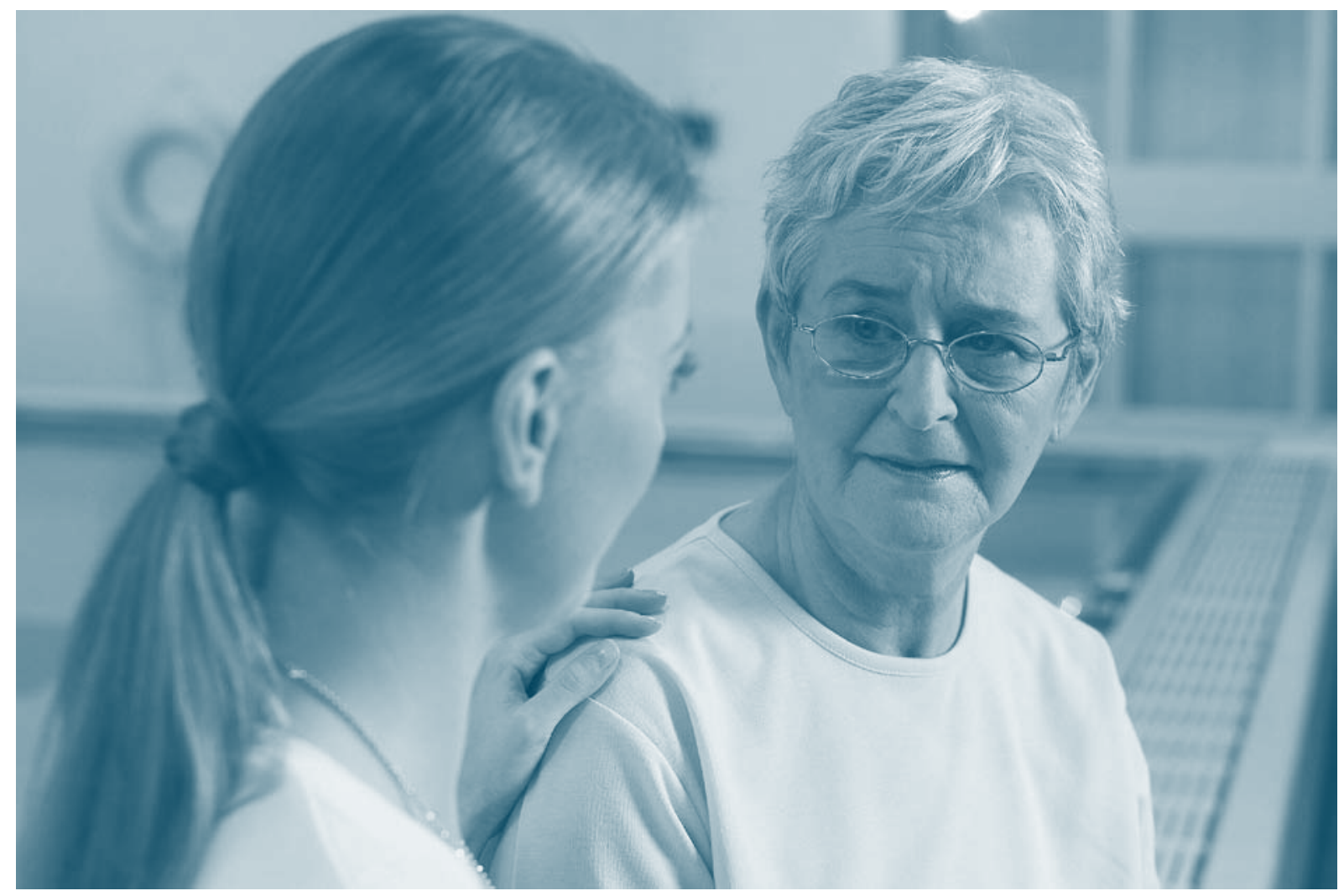

de rol van groepsbegeleider op zich neemt. Dit kan gedurende alle bijeenkomsten dezelfde student zijn, maar de studenten die meedoen aan de gespreksgroep kunnen ook bij toerbeurt groepsbegelei-

De thuisopdrachten waren goed want ik ben geneigd in mijn eigen wereld te blijven, dat geeft een gevoel van veiligheid, maar nu dwingen mij die teksten tot nadenken.

(Wim, 77 jaar)

der zijn. Het strekt tot aanbeveling dat een docent, en/of een ouderejaars student supervisie geeft aan de deelnemende studenten. $\mathrm{Na}$ afloop schrijven de studenten een reflectieverslag, waarin zij hun eigen functioneren, het groepsproces en hun eigen leerervaringen beschrijven en desgewenst koppelen aan literatuur over groepsdynamica en/of over levensloopontwikkeling.

\section{Ontwikkeling en evaluaties}

Aan het Centrum voor Psychogerontologie van de Radboud Universiteit Nijmegen worden studenten al sinds jaar en dag op persoonlijke wijze met ouderen in contact gebracht. Dit gebeurt bijvoorbeeld door studenten in verschillende fases van hun opleiding interviews met ouderen te laten houden, die zij interpreteren met behulp van de hen aangereikte theorieën. In de bachelor-opleiding kunnen studenten ook het vak groepswerk met ouderen kiezen. In dit vak begeleiden studenten onder supervisie van een ervaren docent onder andere ondersteuningsgroepen voor ouderen (Van Kordelaar \& Stevens, 2007). Ook de gesprekgroep Tijdreizen kan gekozen worden. In deze gespreksgroep wordt van de studenten ook verwacht om over zichzelf te reflecteren en dit in het groepsproces in te brengen. Dit vergroot de didactische mogelijkheden van de gespreksgroep.

In vier pilot-groepen werden de algemene werkwijze en de verschillende thema's uitgeprobeerd. Deze groepen hebben plaatsgevonden met studenten van de Radboud Universiteit, de Hogeschool Arnhem-Nijmegen en het ROC-Nijmegen. De ouderen werden geworven middels de Stichting Welzijn Ou-

\section{De gespreksgroep was nog leuker, interes- santer en leerzamer dan ik had verwacht. Ook waren de verschillen tussen jong en oud veel kleiner dan ik dacht.}

(Sanne, 21 jaar)

deren Nijmegen, het Oud Burgeren Gasthuis en verzorgingshuis Nijevelt. Deze vier groepen zijn uitgebreid geëvalueerd met de deelnemers en op basis van deze evaluaties zijn de opdrachten voor thuis en voor in de groep bijgesteld. Ook is op basis van de testgroepen een praktische handleiding voor de groepen geschreven. 


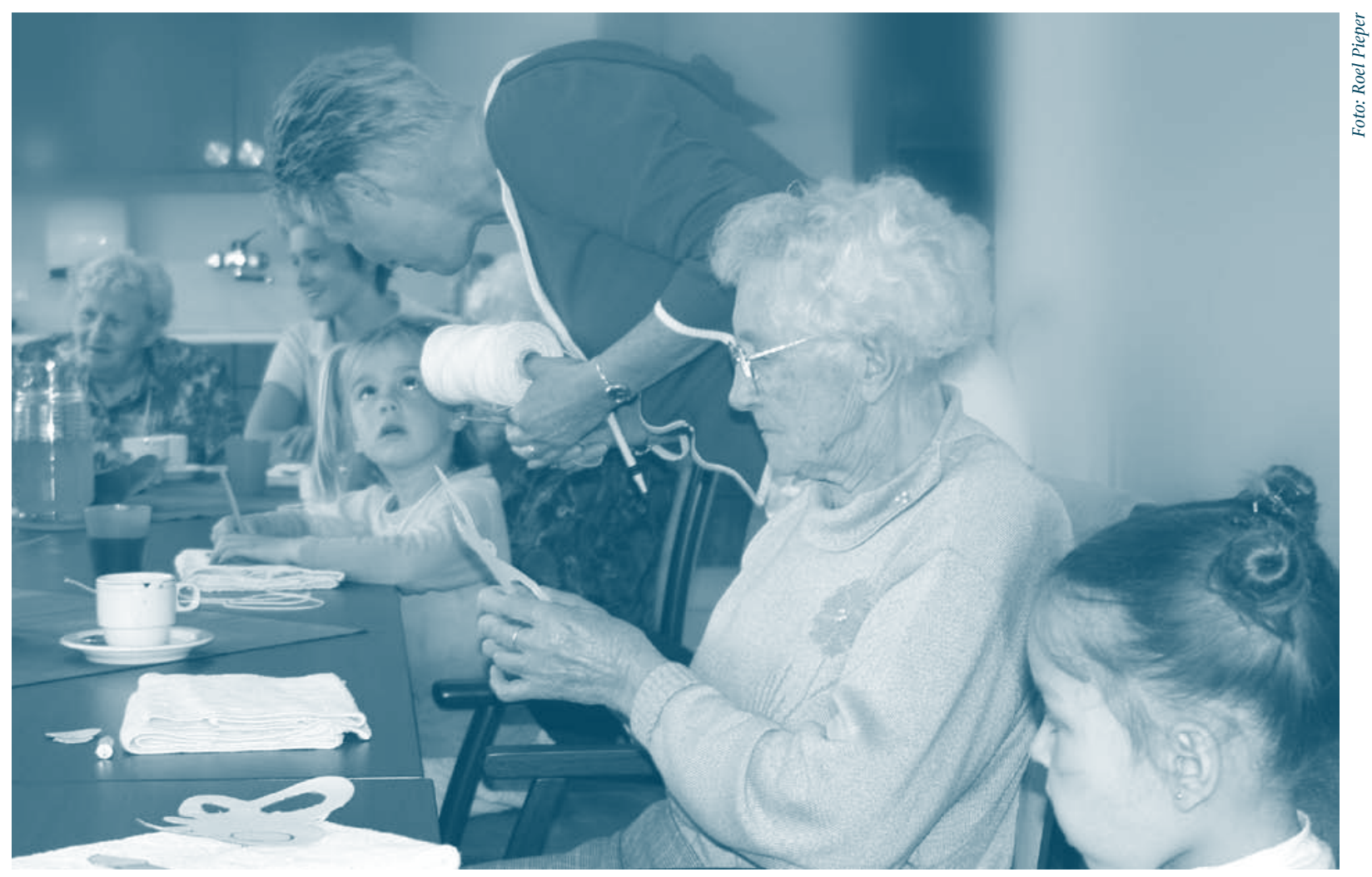

Uit de evaluaties van deze groepen blijkt dat jongeren en ouderen de verschillende thema's doorgaans met een 8 waarderen. Ze stellen het zeer op prijs om de andere generatie

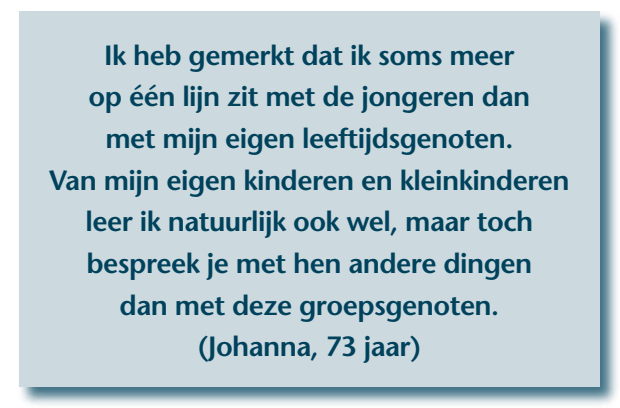

beter te leren kennen. De doelen van de gespreksgroep zijn gehaald, omdat deelnemers aangaven de overeenkomsten tussen de generaties en de verschillen tussen leden van elke generatie beter te zijn gaan zien.

\section{Praktische informatie}

Tijdreizen is ontwikkeld aan het Centrum voor Psychogerontologie van de Radboud Universiteit Nijmegen. Het boek bevat een theoretische inleiding over levensloopontwikkeling, een handleiding voor het opzetten en uitvoeren van een gesprekgroep en veertien thema's met inleidende teksten, thuisopdrachten en groepsopdrachten. Het boek bevat tevens een CD-ROM met alle teksten die ook in het boek zijn opgenomen. Meer informatie is te vinden op www.socsci.kun.nl/psy/ger/tijdreizen.

\section{Geraadpleegde literatuur}

- American Psychological Association. Guidelines for psychological practice with older adults. American Psychologist (2004), 59, pp. 236-260.

- Beullens, J., Marcoen, A., Jaspaert, H., \& Pelemans, W. Het beeld van ouderen bij geneeskundestudenten en de invloed van het medisch onderwijs. Tijdschrift voor Gerontologie en Geriatrie, (1997), 28, pp. 178-83.

- Hagestad, G. O., \& Uhlenberg, P. The social separation of old and young: A root of ageism. Journal of Social Issues, (2005), 61, pp. 343-360.

- Kite, M. E. \& Johnson, B. T. Attitudes towards older and younger adults: A metaanalysis. Psychology and Aging, (1988), 3, 233-244.

- Kordelaar, K. van, \& Stevens, N. Ondersteuningsgroepen. In A.M. Pot, Y. Kuin \& M. T. Vink (Eds.), Handboek Ouderenpsychologie (pp. 293-300). Utrecht: Tijdstroom, 2007.

- Kordelaar, K. van, Vlak, A., Kuin, Y., \& Westerhof, G. (2007). Tijdreizen: Een handleiding en werkboek voor intergenerationele gesprekken. Nijmegen: Centrum voor Psychogerontologie, Radboud Universiteit Nijmegen.

- Kordelaar, K. van, \& Westerhof, G. J. De stille generatie aan het woord. In E. Bohlmeijer, L. Mies, \& G. J. Westerhof. (Eds.). De betekenis van levensverhalen (pp. 219-228). Houten: Bohn Stafleu van Loghum, 2007.

- Pool, A., \& Schumacher, J. HBO Competentieprofiel Verpleegkundige Gerontologie en Geriatrie. Utrecht NIZW, 2005.

- Versteegh, E., \& Westerhof, G. J. Wederzijdse stereotypen van jongeren en ouderen en hun relatie met zelfbeeld en zelfwaardering. Tijdschrift voor Gerontologie en Geriatrie, (2007), 38, 28-36.

- Walker, A., \& Maltby, T. Ageing Europe. Buckingham: Open University Press, 1997.

- Westerhof, G. J., \& Tulle, E. Meanings of ageing and old age: Discursive contexts, social attitudes and personal identities. In J. Bond, S. Peace, F. Dittmann-Kohli, \& G. J. Westerhof (Eds.), Ageing in society (3rd Ed., pp. 235-254). London: Sage, 2007.

* Gerben J. Westerhof, Karen van Kordelaar, Astrid Vlak en Yolande

Kuin zijn werkzaam bij het Centrum voor Psychogerontologie,

Radboud Universiteit Nijmegen. E-mail: g.westerhof@psych.ru.nl 